\title{
The Archives of Sexual Behavior: 40 Years On
}

\author{
Kenneth J. Zucker
}

Published online: 19 January 2011

(C) Springer Science+Business Media, LLC 2011

With this issue, Archives turns 40. For the modern-day historian of sexological scholarship, something is not right. After all, Vol. 1 of Archives was published in 1971. Any expert in hierarchical linear modeling would know that we should be at Vol. 41. Alas, it turns out that Vol. 2 spanned two years (19721973). Perhaps there was a shortage of new submissions back in the day. Perhaps the Founding Editor was dreaming of law school and missed some publication deadline. Whatever. In this Editorial, I will take the reader through an update on the Journal's operations (see also Zucker, 2002; Zucker \& Cantor, 2003, 2005, 2006, 2008, 2009) and other matters.

\section{The Impact Factor}

Calculated each year by the Web of Science ${ }^{\circledR}$ (Thomson Reuters), a journal's impact factor (IF) for a given year is a measure of the frequency with which its recent articles are cited on average during that year. "Recent" refers to the two prior calendar years. Thus, Archives' $2009 \mathrm{IF}$ is the number of times that its 2008 and 2007 articles were cited in 2009, divided by the number of articles the Archives published in 2007 and 2008. Although the IF is the best known metric for citation analysis, there are other measures, including the Immediacy Index (II) and the Cited Half-Life (CHL). The II is a measure of how frequently the journal's "average article" is cited the same year in which it is published. Thus, the II for a year is calculated as the number of times articles from that journal are cited during that year, divided by the number of articles that journal

\section{K. J. Zucker $(\square)$}

Gender Identity Service, Child, Youth, and Family Program, Centre for Addiction and Mental Health, 250 College St., Toronto, ON M5T 1R8, Canada

e-mail: Ken_Zucker@camh.net published that year. The CHL is a measure of the longevity of the frequency of citations to articles in the journal, that is, for how long the average article maintains its currency. The CHL for a year is determined by the time required to account for a cumulative total of $50 \%$ of that year's citations to the journal.

Table 1 shows the IF of the sex and gender periodicals, broadly defined, for the year 2009. The IF of Archives had a nice jump from 2.30 in 2008 to 3.23 in 2009. The meaning of the IF can be crudely gauged in comparative perspective: For 2009, of 2,242 Social Science journals, Archives was ranked 115th (95th percentile). Of 93 journals classified as Psychology (Clinical), Archives was ranked 9th (90th percentile). Of 68 journals classified as Social Science, Interdisciplinary, Archives was ranked 1st. Two of my favorite journals, Evolution and Human Behavior and Hormones and Behavior, are a mere .36 and .54 points away. Can I bring out my bow and arrow now? Of course, an Editor's greatest anxiety about an IF going up is: What if it goes down? The Editor of Journal of Sexual Medicine has witnessed a decrease from 6.19 in 2007 to a mere 5.39 and 4.88 in 2008 and 2009, respectively. One recourse in explaining the drop is to use an incorrect formula in calculating the IF (Goldstein, 2010). There are many Editors who would die for an IF greater than 4.

In previous Editorials, I have observed that there are many sex and gender journals that are not given an IF by the Web of Science ${ }^{\circledR}$. I am pleased to note in Table 1 that Men and Masculinities has now entered the numbers game, as has the widely read Feministische Studien. Starting in 2010, Psychology of Men \& Masculinity (see Sánchez, 2010) and the International Journal of Sexual Health will join the pack. I would still like to see some other periodicals, such as International Journal of Transgenderism, Journal of Gay \& Lesbian Mental Health, Sexologies, and Sexualities, make their way into the game. The formerly electronic only Sexuality Research and Social Policy has now been transformed into a 
Table 1 Impact factor for the year 2009: sex- and gender-related journals $(N=56)$

\begin{tabular}{|c|c|c|c|c|c|}
\hline Journal & Impact factor & 2009 Total cites & 2009 Articles & Immediacy index & Cited half-life \\
\hline Archives of Sexual Behavior & 3.239 & 2,583 & 86 & 0.651 & 7.1 \\
\hline AIDS & 4.909 & 19,911 & 314 & 1.150 & 6.0 \\
\hline Journal of Sexual Medicine & 4.884 & 4,088 & 374 & 0.634 & 2.3 \\
\hline Psychoneuroendocrinology & 4.194 & 6,284 & 170 & 0.912 & 5.8 \\
\hline Fertility and Sterility & 3.970 & 24,036 & 712 & 0.654 & 7.2 \\
\hline AIDS Reviews & 3.786 & 591 & 21 & 0.333 & 4.7 \\
\hline Hormones and Behavior & 3.770 & 6,231 & 148 & 0.709 & 6.0 \\
\hline International Journal of Andrology & 3.705 & 2,259 & 78 & 0.538 & 5.3 \\
\hline Evolution and Human Behavior & 3.594 & 1,858 & 47 & 0.426 & 6.1 \\
\hline Menopause & 3.082 & 2,746 & 151 & 0.967 & 3.8 \\
\hline AIDS and Behavior & 3.038 & 1,998 & 140 & 0.514 & 3.6 \\
\hline Sexual Development & 2.985 & 210 & 28 & 0.179 & 2.1 \\
\hline International Journal of Impotence Research & 2.727 & 2,499 & 54 & 0.593 & 6.0 \\
\hline AIDS Patient Care and STDs & 2.683 & 1,690 & 125 & 0.232 & 4.2 \\
\hline Sexually Transmitted Diseases & 2.579 & 4,440 & 150 & 0.507 & 5.9 \\
\hline Journal of Sex \& Marital Therapy & 2.264 & 1,315 & 28 & 0.071 & 8.1 \\
\hline Perspectives on Sexual and Reproductive Health & 2.220 & 724 & 25 & 0.160 & 5.3 \\
\hline Sexual Abuse: A Journal of Research and Treatment & 2.208 & 699 & 27 & 0.185 & 6.0 \\
\hline Body Image & 2.193 & 593 & 53 & 0.245 & 4.0 \\
\hline Sexually Transmitted Infections & 2.175 & 3,224 & 123 & 1.106 & 5.1 \\
\hline Journal of Women's Health & 1.770 & 1,592 & 217 & 0.157 & 3.8 \\
\hline AIDS Care & 1.684 & 2,951 & 197 & 0.183 & 5.5 \\
\hline Sexual Health & 1.613 & 315 & 53 & 0.113 & 2.8 \\
\hline AIDS Education and Prevention & 1.506 & 1,244 & 65 & 0.046 & 6.9 \\
\hline Gender and Society & 1.339 & 1,732 & 28 & 0.286 & $>10.0$ \\
\hline Psychology of Women Quarterly & 1.297 & 1,620 & 43 & 0.512 & $>10.0$ \\
\hline Women's Health Issues & 1.269 & 619 & 50 & 0.220 & 5.4 \\
\hline Journal of Psychosomatic Obstetrics and Gynecology & 1.197 & 790 & 40 & 0.175 & 8.5 \\
\hline Culture, Health, and Sexuality & 1.068 & 489 & 51 & 0.216 & 4.5 \\
\hline Journal of Sex Research & 1.060 & 1,632 & 47 & 0.255 & $>10.0$ \\
\hline International Journal of STD and AIDS & 1.050 & 2,428 & 214 & 0.360 & 5.9 \\
\hline Gender, Place, and Culture & 1.043 & 466 & 36 & 0.000 & 7.1 \\
\hline Sex Roles & 0.928 & 3,539 & 135 & 0.081 & 10.0 \\
\hline Sexuality and Disability & 0.800 & 299 & 22 & 0.091 & 8.8 \\
\hline European Journal of Women's Studies & 0.763 & 180 & 18 & 0.056 & 4.2 \\
\hline Women \& Health & 0.740 & 1,048 & 33 & 0.061 & 8.1 \\
\hline Gender and Education & 0.731 & 527 & 46 & 0.043 & 7.0 \\
\hline Body \& Society & 0.652 & 510 & 25 & .160 & 8.7 \\
\hline Men and Masculinities & 0.526 & 242 & 28 & 0.071 & 6.8 \\
\hline Feminism and Psychology & 0.514 & 398 & 44 & 0.023 & 7.5 \\
\hline Journal of Gender Studies & 0.452 & 105 & 6 & 0.000 & 6.6 \\
\hline Feminist Review & 0.431 & 303 & 23 & 0.043 & $>10.0$ \\
\hline Signs & 0.424 & 1,179 & 53 & 0.132 & $>10.0$ \\
\hline GLQ: A Journal of Gay and Lesbian Studies & 0.404 & 194 & 19 & 0.053 & 8.2 \\
\hline Women's Studies International Forum & 0.367 & 602 & 51 & 0.020 & 9.6 \\
\hline Journal of Homosexuality & 0.286 & 1,005 & 56 & 0.018 & $>10.0$ \\
\hline Asian Journal of Women's Studies & 0.258 & 48 & 17 & 0.059 & \\
\hline Australian Feminist Studies & 0.217 & 104 & 27 & 0.037 & 8.0 \\
\hline
\end{tabular}


Table 1 continued

\begin{tabular}{llcccc}
\hline Journal & Impact factor & 2009 Total cites & 2009 Articles & Immediacy index & Cited half-life \\
\hline Women and Therapy & 0.171 & 181 & 28 & 0.143 & 8.9 \\
Journal of the History of Sexuality & 0.125 & 162 & 19 & 0.053 & 8.6 \\
Frontiers: Journal of Women's Studies & 0.121 & 92 & 28 & 0.000 & 0.000 \\
Feminist Studies & 0.087 & 419 & 18 & 0.000 & $>10.0$
\end{tabular}

Note: Total cites means the number of references cited in the articles published in the journal in 2009. Immediacy index means cites in 2009 to articles published in 2009/number of articles published in 2009. Cited half-life is the median age of its articles cited in the current year. Half of the citations to the journal are to articles published within the cited half-life

print journal (Vol. 7 in 2010), published by Springer; hopefully, it too will have an IF someday. It will also be of interest to see how a new periodical, Psychology \& Sexuality (Vol. 1 in 2010), will compete in the sexological marketplace. With its "progressive" editorial policy of a "strongly non-pathological stance," it will surely attract many contributors. On the other hand, its policy on submissions that "[treat] sexualities, of any kind, as pathology and in need of treatment and cure will not be acceptable...[r]esearch and writing that is only about the biology of sexualities and/or that which seeks to identify the 'causes' of sexualities will also not be within the remit of this journal" (Langdridge \& Barker, 2010) may result in some sexological scientists applying to a different country club.

\section{Submissions and Disposition}

Figure 1 shows the number of original submissions to the Journal between 2002 and 2010. In 2010, Archives almost reached 300 new submissions, a remarkable increase from 80 in 2002.

Figure 2 shows the Editorial decision data for the original submissions as a function of year (2002-2009). The percentage of manuscripts that were accepted or provisionally accepted

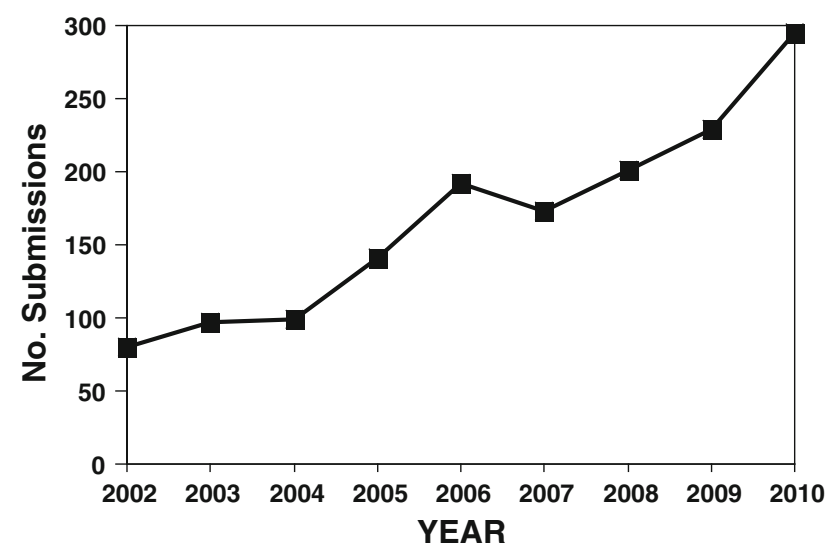

Fig. 1 Number of submissions (2002-2010)

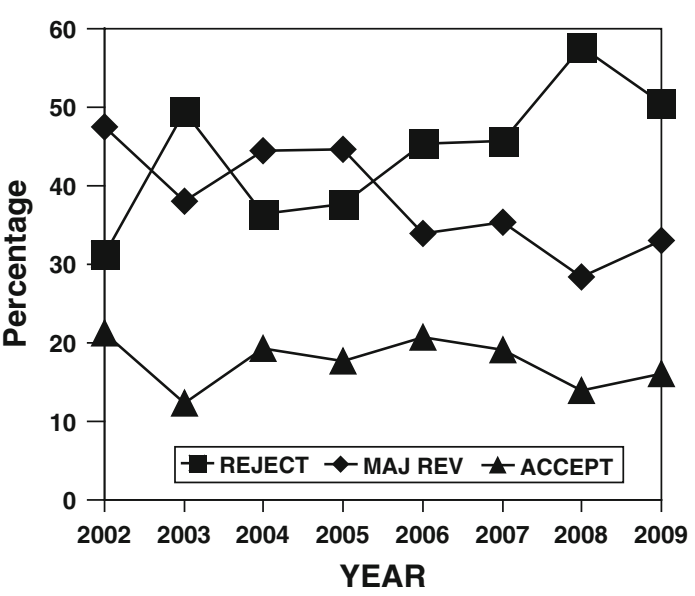

Fig. 2 Manuscript disposition after initial submission (2002-2009)

ranged from 12.4 to $21.2 \%$; the percentage of manuscripts that were subject to major revision ranged from 28.4 to $47.5 \%$; and the percentage of manuscripts that were rejected ranged from 31.2 to $57.7 \%$.

An important question pertains to the fate of the manuscripts with an Editorial decision of "major revision" (revise and resubmit). Between 2002 and 2008, 362 submissions were in this category. Of these, 269 (74.3\%) were accepted for publication after revision, 82 (22.7\%) were not resubmitted, and 11 (3.0\%) were rejected. One can only assume that the manuscripts not resubmitted have been published elsewhere or are gathering dust in the file drawer. With the increase in submissions, this means that the queue for publication is longer. This points to the importance of advance online publication, which has been operational now for several years. Interested readers can track papers that are online first ahead of print by simply typing the name of the journal when accessing PubMed or the Springer link to Archives. The Journal has accommodated the increased number of accepted manuscripts, in part, with an increase in allocated page numbers. We had 1,476 printed pages in 2010. For this, we owe our continued thanks to Carol Bischoff at Springer for her steady commitment to the success of the Journal. 


\section{On the Relationship Between Archives and the International Academy of Sex Research}

For many years now, the Archives has been the official publication of the International Academy of Sex Research (IASR). In 2010, the Academy officers (Cynthia Graham, Erick Janssen, Eli Coleman, and Lin Myers) hammered out a new agreement with the publisher that is worth sharing with the readership. Springer has generously agreed to provide a yearly stipend to the Academy to award Best Poster Presentations and Best Brief Communications (including those by graduate students). The awards for 2010 from the meeting in Prague will be announced in a subsequent issue. Springer has also generously reduced the annual subscription cost to the IASR membership. Again, we owe our thanks to Carol Bischoff for all of this.

\section{Transitions}

In this first issue for 2011, the careful reader of the inside cover will detect some changes to the Editorial Board. Drs. Peter M. Bentler, Dennis McFadden, and Niklas Långström have stepped down from the Board. Peter Bentler has served the Journal for a long time, starting in 1977. His wise statistical expertise has been invaluable. Dennis McFadden served since 2007 as one of my 2D:4D experts and his reviews strengthened many of these submissions. I hope his departure will make his "emeritus status" at the University of Texas more enjoyable.

The British playwright J. M. Barrie wrote that "Nothing is really work unless you would rather be doing something else." Believe me, I take great pleasure in the honor of being the
Editor of Archives. But $\sim 300$ new submissions/year has lessened the fun. It's beyond my saturation point. Accordingly, I am pleased to announce that, effective 2011, the Journal has five new Associate Editors who will handle some of the submissions in their domains of expertise: Lori A. Brotto, Michael P. Carey, Shari L. Dworkin, Marta Meana, and Jeffrey T. Parsons. It's time to share the fun.

\section{References}

Goldstein, I. (2010). Update on the JSM impact factor [Editorial Comment]. Journal of Sexual Medicine, 7, 2913.

Langdridge, D., \& Barker, M. (2010). Editorial. Psychology \& Sexuality, $1,1-2$.

Sánchez, F. J. (2010). Assessing the impact of Psychology of Men \& Masculinity, 2000-2008. Psychology of Men \& Masculinity, 11, 161-169.

Zucker, K. J. (2002). From the Editor's desk: Receiving the torch in the era of sexology's renaissance. Archives of Sexual Behavior, 31, $1-6$.

Zucker, K. J., \& Cantor, J. M. (2003). The numbers game: The impact factor and all that jazz [Editorial]. Archives of Sexual Behavior, 32, $3-5$.

Zucker, K. J., \& Cantor, J. M. (2005). The impact factor: "Goin' up" [Editorial]. Archives of Sexual Behavior, 34, 7-9.

Zucker, K. J., \& Cantor, J. M. (2006). The impact factor: The Archives breaks from the pack [Editorial]. Archives of Sexual Behavior, 35, 7-9.

Zucker, K. J., \& Cantor, J. M. (2008). The Archives in the era of online first ahead of print [Editorial]. Archives of Sexual Behavior, 37, 512-516.

Zucker, K. J., \& Cantor, J. M. (2009). Cruising: Impact factor data [Editorial]. Archives of Sexual Behavior, 38, 878-882. 